\title{
Research on Cultivation of Humanistic Quality of Medical Students
}

\author{
Shidi Wen ${ }^{1}$, Yi Zhang ${ }^{2}$ \\ ${ }^{1}$ Gannan Medical University, Ganzhou, Jiangxi, China, 341000 \\ ${ }^{2}$ Gannan Medical University, Ganzhou, Jiangxi, China, 341000 \\ hunter2011@foxmail.com
}

Keywords: Humanistic quality, Medical students, Humanistic education.

\begin{abstract}
Currently, the teachers and students in medical universities attach importance to the professional learning, while ignoring the humanistic education. This paper gives the concept of humanistic quality, expounds the three parts of humanistic quality education of medical students, and finally gives the suggestions such as changing teaching ideology, adding humanistic curriculum, developing second classroom and enhancing teachers' quality to improve humanistic quality of medical students.
\end{abstract}

\section{Concept of Humanistic Quality}

"Humanities" is a concept that covers a wide range of things. In the modern sense, "humanities" mainly refers to the social morality, value idea, aesthetic taste and thinking mode formed in the process of social development. The essence of the humanistic quality education lies in the cultivation of humanistic spirit. Humanistic quality education is the education process. It aims to mankind in the long social activities by the accumulation of spiritual wisdom to cultivate people, educating people, emphasize the value of human moral spirit, attention on the goodness and beauty understanding, guide people to seek the truth, from goodness and beauty, make the person can insight into the life of the purpose and significance of, find the correct way of life. Simply speaking, the "Humanistic Quality Education" means the education to cultivate students' humanistic spirit and to improve students' humanistic quality.

\section{Content of Humanistic Quality Education of Medical Students}

The humanistic quality education of medical students is divided as follows:

Basic Public Education of Humanistic Quality. Based on the overall quality requirements of talents, the basic public education of humanistic quality aims to solve the problem of how to be a moral person. The purpose of the basic public education is to have a noble thought moral character, high quality culture and healthy psychological quality of the comprehensive development of social backbone personnel. This is the basic task of the higher education in all the colleges and universities, and it is also the content of the education in all the colleges and universities. The education content of this part is mainly in grade one or two. This section should include the "Two Courses" education, philosophy, society, history, and psychology, University of Chinese natural dialectics of behavioral science and thinking science education content, to help students establish a correct outlook on life, world outlook and values, to master the correct method of extraction, understanding of the law of social development, enhance the sense of social responsibility, the formation of psychological regulation ability and behavior ability; through the excellent traditional culture, literature and art, improve the aesthetic ability, cultivate noble cultural taste, is conducive to improve the overall quality of students, help students from the social, cultural and historical background to understand the meaning and value of medicine, from the fundamental guarantee of students' enthusiasm for the rapid development of medical science and social adaptation. It has potential, deep and profound meaning to the students' lifelong development.

Basic Medical Education of Humanistic Quality. Based on the understanding of the dual nature of medicine, the basic education of humanistic quality focuses on establishing a correct view 
of medical values. The education content of this part is mainly in grade two or three. The education should include medical ethics and medical society, science of medical law, medical history, introduction to medicine, health economics, medical management, medical insurance, medical technology assessment, medical dialectics and other content, in-depth analysis of the humanism value of medicine, social value, to help medical students a deep understanding of the medical humanities and social connotation, understanding the relationship between medical and social interaction, improve decision-making capability is selected for a medical and social value, moral value judgment and medical behavior, establish a complete and correct medical value. Medical ethics education is the important embodiment of humanistic quality education of medical students, the primary objective of the training of medical personnel is education students as medical workers to love medical career, with lofty dedication spirit and high responsibility sense to treat, treat patients, and promote the formation of good medical ethics. The most important to strengthen the medical students' humanistic quality is to improve the medical students' ethical quality, the process of imparting medical knowledge, to improve their medical ethics, and gradually improve their medical ethics and medical ethics. This is the right direction for the development of medical science and technology in twenty-first Century, and it is of great significance to guarantee the benefit of medical technology.

Professional Medical Education of Humanistic Quality. Based on the specific needs of medical knowledge structure, the professional medical education of humanistic quality cultivates students' comprehensive application of psychological, social and other medical humanities knowledge and means to participate in the process of medical diagnosis and treatment. This is an organic component of modern medical expertise. The new medical model proposed new requirements for medical knowledge structure, thinking and behavior. Doctors should learn to combine biological, psychological, social and other kinds of knowledge and means to combine with the specific medical activities, which is applied to biomedical technology, and applied psychology, sociology, behavior and other means in the micro medical activities to maintain the integrity of human health. The education content of this part is mainly in grade three or four. This part of the education should include medical psychology, social medicine, behavioral medicine, the doctor-patient communication, health education and other professional content. This is a new medical model that requires specific medical skills and means, like biomedical skills. It is one of the medical skills necessary for doctors in twenty-first century.

\section{Cultivation Strategies of Humanistic Quality of Medical Students}

Transform Teaching Ideology. One-sided understanding of university medical teaching objectives has blocked the penetration of humanistic education. The right education thought guides the right education and the reform practice. The core of quality education is the combination of humanistic education and science education. Higher medical education is very important and urgent to establish the concept of quality education because of its specialty. Humanistic quality education is very important for the growth of medical college students. Facing the humanistic quality of medical students is generally low and traditional medical education of humanism ignored reality, call return of the humanistic spirit of medicine and explore the Countermeasures for improving the quality of Medical College Students' Humanistic is endowed in medical education bounden responsibility, higher medical education in China for a long time to learn from the Soviet Union Road of Billing Division of the school, carrying out education in model organisms, although China's medical profession trained a large number of practical talents, but also exposed the drawbacks. Therefore, the educational circles should pay attention to the best combination of science and humanities, the value of the value, and the implementation of the education practice, and to realize the scientific and humane. The cultivation of students' humanistic spirit in medical college is very important. Only in this way can we realize the real change in the medical model, which makes the medical education meet the needs of the new era. Past medical education, too weak cultural cultivation, make the students humanistic quality is not high, the narrow professional education, make the student's vision is not wide, the academic foundation is not strong; too heavy 
utilitarian orientation, make the students basic training is not enough. In twenty-first century, to cultivate high quality medical talents must be determined to change. In the entire medical personnel training process, we should pay attention to the cultivation of humanistic spirit and scientific spirit.

Add Humanistic Curriculum. We also should update the teaching ideas of education and establish the basic position of the humanities in medical education system. In the course system construction, actively explore the law of higher medical education, strengthen the construction of humanities courses, and further improve the curriculum system. The teaching content of medical humanities and social sciences should be kept in combination with the theory and practice. In the teaching of medical humanities and Social Sciences, we should analyze and study the practical problems of human society, and let the students participate in the research and discussion. Medical humanities and social science teaching should pay attention to the training of students' ability, strengthen students' ability to study and analyze the social problems in the medical field. The most important of the teacher is to inspire the students from their own problems to improve themselves, to guide students from the height of philosophy to sum up, experience, understand and reflect on their own. Humanistic spirit is the core of the lofty ideals of truth, goodness and beauty, with the ultimate goal of human freedom and comprehensive development. Teachers should give students the initiative to students, so that students become masters of learning, to respect the students' subjectivity, to guide students to improve themselves, to pay attention to individual differences, to pay attention to personality, many channels to enhance students' noble personality. Form of examination and evaluation means not only meet the to understand medical students master knowledge of Humanities and Social Sciences, and focuses the experience of medical students, analysis, reflection, review and problem solving ability, in a question and answer questions, case writing and to determine error correction.

Develop Second Classroom. Teachers should also seek various forms of humanistic quality education forms while the classroom teaching is not enough. Develop the medical second classroom to carry out various forms of outreach activities, to create a good medical practice and language background atmosphere, to introduce to the students the knowledge of Humanities make it become an important link in the medical teaching. Teachers should be organized to carry out medical broadcasting, foreign cultural customs, film and other teaching activities, the campus medical corner and the form of a variety of medical competition, etc. At the same time, the modern means of science and education, so that students in these various forms of activities gradually realize and improve the work and life of confidence and courage, form a solid academic attitude, noble life philosophy to educational purposes. School to for students to create a positive use of medical stage, such as organizing medical recitation contest, medical poetry recitation contest and medical speech game. Teachers should carry out training of application ability of competitions such as encouraging students majoring in management case analysis, the computer professional students of medical program design. Teachers should use all kinds of social activities to improve students' comprehensive humanistic quality, such as the establishment of long-term cooperative relationship.

Enhance Teachers' Quality. It's another reason of the lack of humanistic quality in university medical teaching that the teachers and students humanistic foundation is weak. They are unable to highlight the humanities education. Nowadays, university medical teachers are basically a "product" of the traditional examination oriented education, which has obvious limitations in the field of vision and human knowledge. Despite this limitation, individual teacher's self-development and self-enrichment and have to make up for, but it is difficult to have a breakthrough change, directly affects the teacher's understanding of the humanistic knowledge and understanding, thereby affecting the penetration of humanistic spirit in the teaching process. And now the university students have a wide range of information sources, but it is not much involved in human knowledge. They tend to blind, emotional, utilitarian and vanity to seize the opportunity to sneak in, occupation their young hearts, affecting their experience and manners of the humanistic spirit, directly affect the humanistic education in university medical teaching in the penetration. In addition, teachers and students lack of exchanges and dialogue and the student assessment method is not scientific also hinders to penetrate the humanities education in university medical teaching. According to the 
present situation, more and more medical professional teachers should be allowed to take part in medical humanities and social sciences.

\section{Conclusion}

It is difficult to have medical excellence without good humanistic knowledge. Therefore, in the process of training medical talents of medical colleges, we must enrich the content of medical humanities education, the mechanism of medical education in time. It is necessary for medical students not only have a wealth of professional knowledge and superb professional skills, but also have good humanistic quality in the health care services in the future.

\section{References}

[1] J. Ye, On the Effectiveness of Medical Humanistic Quality Education, Journal of Liaoning Medical University(Social Science Edition), 5(2014)37-39.

[2] P. Sun, A Study on the Construction of Humanistic Educational System in Medical Universities, Third Military Medical University, 2012.

[3] F. Lin, Studieson Influencing Factors of Humanistic Quality for Medical Students, Southern Medical University, 2010.

[4] T. Liang, L.L. Zheng, J. Liu, The Relationship between Medical Students' Humanistic Quality and Subjective Well-being, China Journal of Health Psychology, 23(2015)1232-1235. 